\title{
Model Remaja Putri: Body Image dan Bulimia Nervosa
}

\section{Teen Model: Body Image and Bulimia Nervosa}

\author{
Siti Mutia Anindita \\ Program Studi Psikologi Universitas Nahdlatul Ulama \\ E-mail: mutia.anindita@unusia.ac.id
}

\begin{abstract}
Abstrak
Perubahan fisik yang sangat cepat menjadikan remaja putri sangat memperhatikan dan memiliki kesadaran tinggi mengenai citra tubuhnya. Citra tubuh yang tidak sehat dan munculnya gangguan citra tubuh (body image disturbance) dapat memberikan dampak buruk bagi remaja putri, yang paling mengkhawatirkan adalah bisa menyebabkan masalah klinis seperti bulimia nervosa atau anoreksia nervosa. Tujuan dari penelitian ini adalah untuk mengetahui hubungan antara citra tubuh dengan kecenderungan gangguan bulimia nervosa pada model remaja putri. Penelitian ini melibatkan 62 responden dari $20 \%$ total populasi model remaja putri. Untuk mengukur citra tubuh menggunakan alat ukur MBSRQ yang dikembangkan oleh Thomas F. Cash (1989) dan telah diadaptasi oleh Jihan Kemala (2002). Sedangkan untuk mengukur kecenderungan bulimia nervosa, peneliti membuat alat ukur faktor-faktor individu yang mengalami gangguan bulimia nervosa, alat ukur tersebut terdiri dari 13 indikator. Penelitian ini menggunakan uji korelasi dengan menggunakan korelasi Spearmen's rho. Hasil penelitian ini menyatakan tidak ada hubungan negatif yang signifikan antara citra tubuh dengan kecenderungan bulimia nervosa pada model remaja putri. Artinya citra tubuh yang positif para model remaja putri tidak diikuti dengan menurunnya kecenderungan gangguan bulimia nervosa secara signifikan.
\end{abstract}

Kata Kunci: model, remaja putri, citra tubuh, bulimia nervosa

\begin{abstract}
The physical changes that very fast in teenage girls make they are very care and has high awareness of their body image. Unhealthy body image and it
\end{abstract}


appear to be body image distubance give negative effects for teenage girls, especially it can be clinical problems such as bulimia nervosa or anorexia nervosa. The purpose of this study is knowing the relationship between body image and tendency to be bulimia nervosa in teenage girl models. This study involved 62 respondents from $20 \%$ of total teenage girl population. To measure the body image, we use the MBSRQ measuring instrument developed by Thomas F. Cash (1989) and adapted by Jihan Kemala (2002). Meanwhile, to measure the tendency of bulimia nervosa, researchers made a measuring instrument for individual factors who experiencing bulimia nervosa disorder, there are 13 indicators in the measuring instrument. The researchers using correlation tes by Spearmen's rho correlation. The result of this study aim that there is nl significant negative relationship between body image and tendency of bulimia nervosa in teenage girl model. It means the positive body image in teenage girl model not allowed with decreasing the tendency of bulimia nervosa significantly.

Keywords: model, teenage girl, body image, bulimia nervosa

\section{Pendahuluan}

Seseorang yang berpenampilan menarik seringkali dianggap sebagai seseorang yang sukses, menyenangkan dan memiliki tingkah laku yang positif. Penampilan fisik yang menarik diidentifikasikan sebagai sosok tubuh ideal, yaitu bentuk tubuh proporsional antara ukuran tinggi dan berat badan. Kurus dan langsing seringkali dianggap masyarakat sebagai sosok yang cantik dan ideal (Rice 1990). Penerimaan masyarakat tentang penampilan fisik yang menarik inilah yang mempengaruhi kaum perempuan mempunyai obsesi mencapai tubuh yang cantik dan ideal.

Sering sekali ditemukan remaja yang merasa tidak percaya diri dengan penampilannya. Penilaian akan dirinya menjadi negatif manakala remaja melihat penampilan fisiknya tidak ideal atau tidak cantik menurut penilaian masyarakat pada umumnya. Maka jadilah kecantikan fisik diagung-agungkan. Sebab sejak dulu yang populer di masyarakat sebagai orang yang cantik, adalah orang yang langsing, kulitnya putih, rambutnya indah dan keindahan-keindahan fisik lainnya bagi wanita. Orang yang memiliki penampilan fisik yang cantik cenderung dinilai mempunyai banyak peluang dan kesempatan di sana-sini dibandingkan dengan orang yang penampilannya "biasa-biasa saja" (Sari 2006). Sehingga remaja yang jiwanya masih labil cenderung melihat bahwa penampilan adalah segala-galanya. Yang akan menjadi popular adalah yang penampilan fisiknya cantik.

Perkembangan mode merupakan informasi yang selalu berkembang dengan cepat dari tahun ke tahun. Penampilan menjadi suatu hal yang penting bagi semua orang. Biasanya penampilan yang dapat dikatakan trendy itu menuntut kesempurnaan tampilan fisik dan bentuk tubuh yang ideal, sehingga apapun jenis gaya fesyen ataupun kosmetik sedang populer menjadi cocok dan pantas jika disandingkan dengan penampilan fisik dan bentuk tubuh yang ideal. Semua orang 
menjadi dituntut untuk terus mengikuti tren yang ada, tak terkecuali remaja. Maka semua orang termasuk remaja berlomba-lomba untuk menjadikan penampilan fisik dan bentuk tubuhnya menjadi ideal dengan cara apapun (Sari 2006).

Kehadiran media, tidak dipungkiri semakin mendorong seseorang untuk meletakkan standar ideal penampilannya menurut penilaian masyarakat. Kecantikan serta kesempurnaan fisik menjadi ukuran ideal bagi seseorang sehingga banyak yang mengejar kesempurnaan fisik itu dengan "vermak" tubuh dan wajah, bantuan kosmetik, memilih gaya busana yang up to date, ke salon untuk menata rambut mode mutakhir dan lain-lain. Meletakkan penilaian dan penerimaan sosial di atas segala-galanya hanya akan membuat seseorang menjadi stress, gagal untuk menjadi dirinya sendiri dan kehilangan kepercayaan dirinya (Kemala 2002).

Perempuan sering menjadi sasaran baik sebagai model maupun target pasar dari iklan produk kecantikan yang ditawarkan oleh media iklan. Banyak model iklan adalah perempuan. Hal ini dilakukan untuk menarik konsumen perempuan lainnya agar dapat meniru penampilan model iklan tersebut. Sebagai target pasar, perempuan sangat potensial sebagai konsumen, karena adanya perasaan selalu ingin tampil menarik dihadapan lawan jenis sangat mendominasi kepribadiannya. Perempuan akan berlomba-lomba membeli produk yang ditawarkan untuk tampil cantik dan menarik ala model, yang mereka konsumsi untuk menunjukkan eksistensinya dihadapan lawan jenis (Fasli 2007).

Menurut Lerner (dalam Thompson 1999), bahwa bentuk tubuh lebih memiliki pengaruh yang besar pada remaja putri, karena pada remaja putra hal yang lebih berpengaruh adalah fungsi tubuhnya. Pernyataan tersebut juga sesuai dengan penelitian yang dilakukan Serdula, Collins, Williamson, Anda, Pamuk, dan Byers (dalam Thompson 1999) yang memperoleh data bahwa diantara 11.467 murid SMA di Amerika Serikat sebanyak 44\% remaja putri dan 15\% remaja putra menginginkan untuk menurunkan berat badan. Melalui penelitian tersebut dapat dilihat bahwa citra tubuh lebih berpengaruh pada remaja putri dibandingkan dengan remaja putra.

Seseorang dengan citra tubuh yang negatif memiliki pemikiran yang negatif dan kritis tentang tubuhnya dan sering tidak mampu mempersepsikan ukuran dan bentuk tubuh secara akurat (Thompson 1996). Pandangan negatif dan ketidak puasan seseorang terhadap tubuhnya dapat menyebabkan gangguan citra tubuh (body image disturbance).

Citra tubuh seseorang berkembang dalam konteks budaya (Fallon 1990 dalam Thompson 1996). Norma budaya memiliki peranan dalam mempengaruhi perkembangan tingkah laku dan sikap yang berhubungan dengan kepuasan citra tubuh (Thompson 1996). Budaya lain mungkin kurang berfokus pada berat badan dibandingkan dengan budaya barat. Sebagai contoh, pada suatu penelitian yang melibatkan populasi imigran Cina di Amerika Serikat ditemukan bahwa atribut fisik yang diidealkan adalah mata yang lebih lebar serta kaki yang lebih kecil (Thompson 1996).

Hasil wawancara peneliti dengan salah satu model remaja putri pada tanggal 30 April 2009, bahwa seseorang yang berprofesi sebagai seorang model 
harus tetap menjaga berat badannya agar berbagai macam pakaian cukup dan sesuai dengan bentuk tubuhnya jika dipakai oleh sang model. Agar berat badan selalu terjaga, sang model harus mengatur pola makan sehari-harinya dengan cara mengurangi makan-makanan berkabohidrat dan berlemak, mereka harus selalu mengkonsumsi buah dan sayur-sayuran yang mengandung banyak serat, mineral dan vitamin. Bahkan ketika ingin tampil di catwalk tiga hari sebelum penampilannya para model sebisa mungkin untuk berpuasa, agar lingkar perut dan lingar pinggang sesuai dengan pakaian yang akan digunakan dan menarik jika dilihat oleh para desainer dan penonton. Beberapa model di Indonesia untuk menjaga berat badannya dapat melakukan diet ketat atau tidak makan sama sekali dalam beberapa hari, ada juga model yang setelah makan memuntahkan kembali makanan tersebut karena merasa takut jika makan akan merubah berat badan, lingkar perut dan lingkar pinggul.

\section{Tinjauan Pustaka dan Alur Logika Penelitian}

Penelitian ini memberikan banyak masukan terhadap perkembangan remaja dan membuat kita sadar bahwa masalah yang berhubungan dengan gangguan citra tubuh pada remaja semakin banyak. Gangguan citra tubuh lebih banyak dialami oleh remaja putri dibanding oleh remaja putra. Dari hasil dari sebuah penelitian, ditemukan bahwa remaja perempuan lebih merasa tidak puas terhadap tubuhnya dibanding remaja laki-laki (Santrock 2003). Ditemukan juga bahwa anak perempuan lebih mempunyai anggapan bahwa tubuh yang kurus dapat meningkatkan kesempatan mereka untuk disukai (Thompson, et al. 1999).

Citra tubuh yang tidak sehat dan munculnya gangguan citra tubuh (body image disturbance) hanya memberikan dampak buruk bagi seseorang. Dampaknya pun bermacam-macam, seperti lelah, tidak bertenaga karena berdiet, gangguan emosional, moody, sering cemas, stress, tidak bisa berkonsentrasi, prestasi menurun, berkurangnya semangat, menurunnya minat seksual dan yang paling mengkhawatirkan adalah bisa menyebabkan masalah klinis seperti anoreksi nervosa atau bulimia nervosa. Panduan American Psichiatric Assosiation [APA] (2000) yang tertuang dalam The Diagnostic and Statistical Manual of Mental Disorder [DSMIV]-IV-TR menjelaskan bahwa anoreksi nervosa adalah gangguan makan karena adanya keinginan yang keras untuk mendapatkan tubuh yang kurus dengan cara melaparkan diri dan mempunyai ketakutan yang sangat besar akan kegemukan. Sedangkan bulimia nervosa adalah gangguan makan dimana individu secara konsisten menjalani pola makan berlebihan dan kemudian memuntahkannya kembali.

Dalam Thompson (1996) dijelaskan bahwa bulimia nervosa adalah gangguan pola makan dimana seseorang makan dalam porsi yang sangat besar dalam waktu yang singkat, dan mengambil tindakan-tindakan pencegahan agar kalori tersebut tidak terserap oleh tubuh dan berat badan tidak bertambah. Macam tindakan preventif ini bervariasi, mulai dari memuntahkan kembali makanan, puasa, atau menggunakan obat-obatan. Jika tidak, ia akan merasa tidak nyaman secara psikologis karena takut akan efek "menggemukan" dari makanan yang telah 
dikonsumsinya. Penderita biasanya telah mencoba berbagai macam diet tanpa hasil sebelum akhirnya menderita bulimia nervosa.

Umumnya penderita bulimia nervosa mempunyai berat badan yang dianggap sedikit di atas rata-rata (shightly overweight). Obsesi terhadap berat badan dan bentuk tubuh ini menjadikan penderitanya terlingkupi rasa malu, tidak berdaya dan depresi terhadap pola makan mereka. Gangguan makan ini banyak terjadi pada negara maju dengan masyarakat industri, di mana makanan berlimpah tetapi langsing diasosiasikan dengan menarik. Media baik cetak maupun elektronik menanamkan kepercayaan mengenai standar ideal yang tidak realistik akan tubuh yang kurus, mendorong ketidakpuasan remaja perempuan akan tubuhnya (Thompson 1996).

\section{Bagan}

Alur Logis dan Skema Konseptual

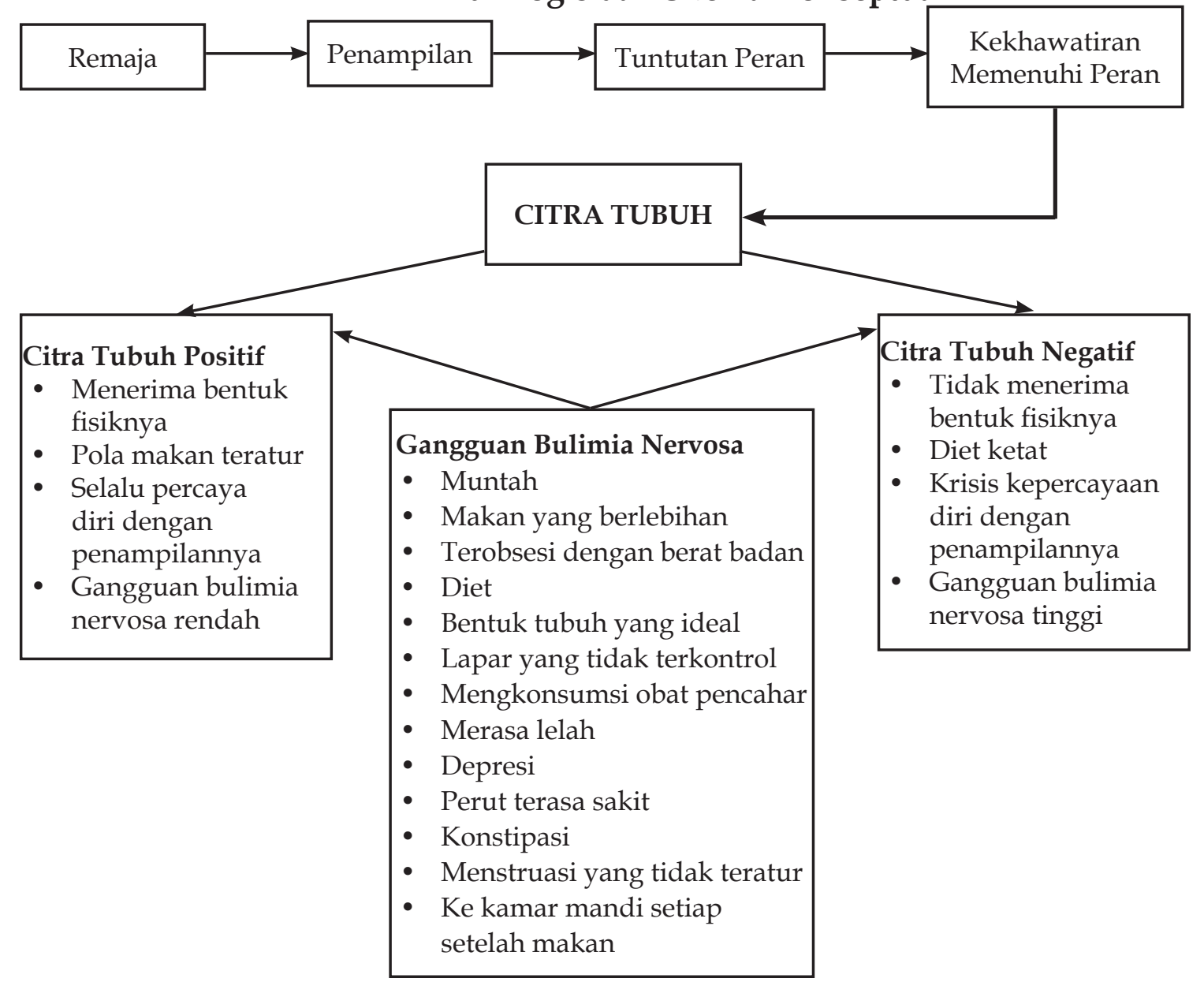

Dari berbagai penjelasan di atas, dapat disimpulkan bahwa tuntutan sosial mempunyai pengaruh terhadap bagaimana pandangan seseorang terhadap tubuhnya. Gangguan citra tubuh menjadi salah satu akibat dari tuntutan sosial ini yang bisa menimbulkan berbagai dampak negatif bagi kehidupan seseorang, terutama remaja putri. Peneliti ingin melihat gambaran citra tubuh pada model remaja putri yang diindikasikan mengidap kecenderungan gangguan bulimia nervosa.

Terkait penjelasan sebelumnya maka pengertian citra tubuh adalah sebuah 
representasi mental mengenai bentuk tubuh kita sendiri (Atwater 1999). Pengertian ini menjelaskan perasaan kita yang sesungguhnya terhadap tubuh kita sendiri, termasuk di dalamnya perasaan puas atau ketidakpuasan terhadap tubuh kita.

Dari definisi di atas dapat disimpulkan bahwa citra tubuh adalah penilaian seseorang mengenai tubuhnya dan bagaimana perasaannya terhadap tubuhnya tersebut. Seseorang bisa memiliki citra tubuh yang sehat atau tidak sehat. Orang yang dengan citra tubuh sehat memiliki pandangan positif terhadap tubuhnya dimana ia merasa puas dengan tubuhnya. Sedangkan orang dengan citra tubuh yang tidak sehat memiliki pandangan negatif terhadap tubuhnya dimana ia merasa tidak puas dengan tubuhnya (Atwater 1999).

Menurut Thompson (1996), citra tubuh terdiri dari tiga komponen citra tubuh. Pertama persepsi, berhubungan dengan ketepatan individu dalam mempersepsi atau memperkirakan ukuran tubuhnya. Kedua sikap, berhubungan dengan kepuasan individu terhadap tubuhnya, perhatian individu terhadap tubuhnya, kognisi, evaluasi, dan kecemasan individu terhadap penampilan tubuhnya. Ketiga behavioral (tingkah laku), yaitu menitikberatkan pada penghindaran terhadap situasi yang menyebabkan individu mengalami ketidaknyamanan yang berhubungan dengan penampilan fisik.

Citra tubuh merupakan pengalaman multidimensional, meliputi tingkah laku, afeksi, penginderaan, imagery dan kognisi, dan pengalaman interpersonal serta biologi (Thompson 1996). Oleh karena itu, dalam melakukan pengkajian terhadap citra tubuh diperlukan pemahaman yang menyeluruh terhadap komponen-komponennya.

Citra tubuh positif menurut Mintz dan Betz (dalam Thompson 1996) adalah derajat kepuasan individu terhadap bagian-bagian dan karakteristik tubuh yang sangat menjadi perhatian mereka. Pada daerah tubuh, perempuan rata-rata sangat memperhatikan bagian seksualitas tubuhnya, seperti paha, pinggul, dan pantat. Bahkan perempuan yang mempunyai berat badan normal cenderung kurus pun kebanyakan menginginkan paha, pinggul, dan patat yang lebih kecil lagi.

Kepuasan citra tubuh merupakan hasil dari perbandingan antara standar citra tubuh ideal yang ada di masyarakat dengan persepsi tentang citra tubuh nyata yang dimilikinya. Apabila perbandingan antara citra tubuh nyata dan citra tubuh ideal semakin kecil, maka dapat diartikan bahwa terjadi kesesuaian antara citra tubuh nyata dengan citra tubuh ideal sehingga individu merasa puas akan citra tubuhnya atau memiliki citra tubuh positif (Thompson 1996).

Ketidakpuasan terhadap citra tubuh adalah hasil perbandingan antara standar citra tubuh ideal yang ada di masyarakat dengan persepsi citra tubuh nyata yang dimilikinya. Standar citra tubuh yang dianggap ideal di masyarakat adalah bentuk tubuh yang kurus dan langsing, sehingga membuat individu akan berusaha untuk memenuhi standar ideal tersebut. Hal inilah yang membedakan antara citra tubuh yang dimilikinya dengan yang ideal di masyarakat, yang pada akhirnya berkembang menjadi ketidakpuasan terhadap citra tubuh (Thompson 1996).

Citra tubuh negatif disebabkan adanya gangguan (distorsi) dalam komponen 
persepsinya, sehingga individu tidak mampu memperkirakan ukuran tubuhnya secara tepat. Distorsi citra tubuh merupakan perbedaan antara persepsi yang dimiliki individu tentang tubuhnya berbeda (tidak akurat) dengan keadaan tubuh yang sebenarnya. Ketidakakuratan tersebut adalah overestimation dan underestimation. Overestimation, yaitu individu mempersepsi tubuhnya lebih besar daripada ukuran yang sebenarnya, contohnya seorang perempuan yang langsing akan mempersepsi tubuhnya mempunyai ukuran yang sama dengan orang lain yang bertubuh lebih gemuk daripada dirinya. Sedangkan underestimation, yaitu individu mempersepsi tubuhnya lebih kecil daripada ukuran tubuh yang sebenarnya. Tetapi tidak semua individu mempunyai citra tubuh negatif mengalami distorsi pada komponen persepsinya (Friedman \& Brownell, dalam Thompson 1996).

Seseorang dikatakan memiliki citra tubuh yang negatif apabila derajat kepuasan penampilan fisik tubuhnya rendah. Citra tubuh yang negatif dapat mempengaruhi kehidupan seseorang, timbul harga diri yang rendah, bahkan timbul gangguan kebiasaan makan karena seseorang berusaha memperbaiki penampilan fisik tubuhnya dengan cara yang salah (Thompson 1996).

Menurut Wright (dalam Santrock 2003), harapan seseorang terhadap citra tubuh yang ideal akan terus menguat sampai remaja. Tobin-Richards, Boxer, dan Petersen (dalam Santrock 2003) menambahkan bahwa remaja perempuan memiliki kecenderungan untuk bersikap positif terhadap tubuh mereka ketika sedang merasa mengalami kekurangan berat badan (underweight). Kepuasan remaja akan citra tubuhnya menjadi sangat penting dan dapat menunjukkan peranan yang signifikan dalam memprediksi munculnya depresi, gangguan makan dan self esteem rendah (Jones, dalam Thompson 1996).

Salah satu gangguan makan yang mempengaruhi kepuasan citra tubuh adalah bulimia nervosa. Bulimia nervosa ditandai dengan makan yang terlalu berlebihan; yaitu seseorang mengalami masa ketika dia makan tanpa kontrol. Biasanya makan yang di luar kontrol ini diikuti dengan muntah yang dipaksa (Herron dan Peter 2003). Hal ini membuat penderita bulimia nervosa mencoba membebaskan diri dari makanan yang sudah dikonsumsinya. Penderita bulimia terobsesi dengan berat badan, makanan, diet, dan bentuk tubuh. Penderita bulimia nervosa ini biasanya tidak hanya menderita secara fisik tetapi juga psikologis.

Penderita bulimia makan berlebihan biasanya dilakukan secara diamdiam dan terus berlangsung hingga orang yang bersangkutan merasa sangat kekenyangan. Setelah selesai makan yang berlebihan, rasa tidak nyaman dan takut bila berat badan naik datang, sehingga membuat penderita bulimia memaksa untuk memuntahkan kembali makanan yang sudah dimakan dengan cara memasukkan jari-jari ke tenggorokkan agar tersedak (Davison, Neale, dan Kring 2006).

Menurut Kaplan, Sadock, dan Grebb (1997), faktor-faktor penyebab bulimia nervosa adalah sebagai berikut:

1. Faktor Biologis

Antidepresan sangat bermanfaat bagi pasien penderita bulimia nervosa.

Kadar endorfin plasma meningkat pada pasien bulimia nervosa yang muntah, 
dan menyebabkan perasaan sehat yang dirasakan pasien setelah muntah.

2. Faktor Sosial

Pasien bulimia nervosa cenderung berespon terhadap tekanan sosial untuk menjadi kurus. Pasien biasanya depresi tinggi. Keluarga pasien bulimia nervosa kurang dekat dan menggambarkan orang tua yang menolak dan menelantarkan.

3. Faktor Psikologis

Pasien bulimia nervosa memiliki emosi yang terlihat, seperti mengungkapkan kemarahan secara terbuka dan impulsif. Penderita bulimia nervosa biasanya makan yang terlalu berlebih. Tidak memiliki super ego dan kekuatan ego. Kesulitan yang dimiliki penderita bulimia nervosa, yaitu ketergantungan zat dan hubungan seksual yang merusak diri sendiri (Kaplan, Sadock, dan Grebb 1997).

Faktor yang sangat mempengaruhi antara citra tubuh dengan kecenderungan bulimia nervosa adalah faktor biologis dan psikologis. Karena penderita gangguan bulimia nervosa cenderung menurun dalam keluarga dan kemungkinan ada genetik (Papalia dan Olds 2008). Dan faktor psikologis mempengaruhi perubahan fisik pada saat pubertas akan menyebabkan remaja sangat memperhatikan bentuk tubuhnya (Santrock 2003). Perhatian yang berlebihan tersebut yang akan menyebabkan remaja terkena gangguan makan, seperti bulimia nervosa dan anoreksia nervosa.

Dalam tulisan ini, saya akan menunjukkan gambaran hubungan citra tubuh dengan kecenderungan gangguan bulimia nervosa pada model remaja putri. Asumsi yang digunakan adalah terdapat hubungan negatif yang signifikan antara citra tubuh dengan kecenderungan gangguan bulimia nervosa pada model remaja putri. Artinya citra tubuh yang positif para model remaja putri tidak diikuti dengan menurunnya kecenderungan gangguan bulimia nervosa secara signifikan. Asumsi ini dijadikan juga sebagai hipotesis dari penelitian ini.

\section{Metode}

Sampel dari penelitian ini adalah bagian dari populasi yang diambil melalui cara-cara tertentu dan memiliki karakteristik tertentu sesuai subjek penelitian. Penelitian dilakukan pada Agency Model di Jakarta yang beranggotakan 628 orang, dengan rincian model dewasa perempuan 228 orang, model remaja perempuan 315 orang, dan model anak-anak 85 orang. Dengan kata lain, populasi penelitian ini adalah seluruh anggota Agency Model tersebut. Menurut Arikunto (2002), jika jumlah subjek suatu populasi bernilai besar, dapat diambil antara 10-15\% atau 20-25\% atau lebih, tergantung setidak-tidaknya dari beberapa hal, salah satunya yaitu kemampuan peneliti dilihat dari waktu, tenaga, dan dana. Maka penulis mengambil jumlah sampel sebanyak $20 \%$ dari jumlah populasi remaja putri yaitu sebanyak 62 sampel.

Penelitian ini teknik pengambilan sampel yang digunakan non probability sampling, yaitu dengan jenis purposive sampling. Menurut Sugiyono (2002), 
nonprobability sampling adalah teknik pengambilan sampel yang tidak memberi peluang atau kesempatan yang sama bagi setiap anggota populasi yang dipilih menjadi sampel. Sedangkan purposive sampling, dilakukan dengan mengambil orang-orang terpilih oleh peneliti menurut ciri-ciri spesifik yang dimiliki oleh sampel itu. Sesuai dengan tujuan penelitian, yang menjadi subjek penelitian ini adalah model remaja putri dengan karakteristik, yaitu usia 13-20 tahun, belum menikah, tinggi badan 165-180 cm, berat badan 40-55 kg, dan tinggal di wilayah Jabodetabek.

Pada penelitian ini terdapat dua variabel dan dua alat ukur. Pertama, MBRSQ (Multidimensional Body-Self Relations Questionnaire) untuk mengukur citra tubuh yang dikembangkan oleh Thomas F. Cash pada tahun 1989 dan diadaptasi oleh Jihan Kemala (2002), lalu diadaptasi kembali untuk penelitian yang melahirkan tulisan ini. Alat ini terdiri atas 10 subskala, meliputi: (1) evaluasi penampilan fisik, (2) orientasi penampilan fisik, (3) evaluasi kebugaran fisik, (4) orientasi kebugaran fisik, (5) evaluasi kesehatan, (6) orientasi kesehatan, (7) orientasi tentang penyakit, (8) kepuasan area tubuh, (9) pengkategorian ukuran tubuh, dan (10) kecemasan menjadi gemuk. Kedua, untuk mengukur variabel kecenderungan gangguan bulimia nervosa digunakan kuesioner untuk memperoleh skor. Skala tersebut terdiri dari 13 indikator, yaitu (1) muntah, (2) makan yang berlebihan, (3) terobsesi dengan berat badan, (4) diet, (5) bentuk tubuh, (6) lapar yang tidak terkontrol, (7) mengkonsumsi obat pencahar, (8) merasa lelah, (9) depresi, (10) perut terasa sakit, (11) konstipasi, (12) menstruasi yang tidak teratur, dan (13) ke kamar mandi setiap setelah makan.

Seluruh data yang terkumpul, dilakukan pengolahan data menggunakan SPSS 11.5. Pengujian hipotesis untuk menjawab pertanyaan utama penelitian ini, apakah terdapat hubungan yang signifikan antara citra tubuh dengan kecenderungan bulimia nervosa, dipergunakan metode korelasi Tata Jenjang (Spearman Correlation).

\section{Temuan dan Analisis}

Analisis statistik untuk menguji hipotesis pada penelitian ini menggunakan korelasi Spearman's rho. Dalam perhitungannya, peneliti menggunakan program SPSS 11.5. Secara singkat, hasil analisis statistik dan uji hipotesis yang telah dilakukan disampaikan di bawah ini.

Hasil uji korelasi dengan teknik Spearman's rho dihasilkan nilai $\mathrm{r}$ hitung sebesar 0.058. Sementara nilai $r$ tabel pada taraf signifikansi 5\% dengan N 62 adalah sebesar 0.364 .

\section{Keputusan:}

H0 diterima jika $r$ hitung $<\mathrm{r}$ table

Karena nilai $\mathrm{r}$ hitung yang didapat $(0.058)<\mathrm{r}$ tabel (Sig. 5\% ; N $62=0.364$ ), maka hipotesis nihil yang menyatakan bahwa tidak terdapat hubungan yang signifikan antara Citra Tubuh dengan Kecenderungan Bulimia diterima. Dengan kata lain, asumsi serta hipotesis yang kami sampaikan dimuka telah dikukuhkan melalui uji hipotesis. Secara detail, hasil uji korelasi ditampilkan di Tabel 1 berikut. 
Tabel 1

Uji Korelasi antara Citra tubuh (MBSRQ) dengan Kecenderungan Bulimia Nervosa

\begin{tabular}{|c|r|r|c|c|}
\hline & & MBSRQ & $\begin{array}{c}\text { Kecenderungan } \\
\text { Bulimia }\end{array}$ \\
\hline \multirow{2}{*}{ Spearman's rho } & Citra Tubuh & $\begin{array}{r}\text { Correlation } \\
\text { Coefficient }\end{array}$ & 1.000 & .058 \\
\hline & & Sig. (2-tailed) & & .654 \\
\cline { 3 - 5 } & & $\mathrm{N}$ & 62 & 62 \\
\cline { 2 - 5 } & $\begin{array}{r}\text { Kecenderungan } \\
\text { Bulimia }\end{array}$ & $\begin{array}{r}\text { Correlation } \\
\text { Coefficient }\end{array}$ & .058 & 1.000 \\
\cline { 2 - 5 } & & Sig. (2-tailed) & .654 & \\
\cline { 2 - 5 } & & $\mathrm{N}$ & 62 & 62 \\
\hline
\end{tabular}

Sumber: Uji Statistik oleh Peneliti

\section{Diskusi}

Hasil penelitian jelas mengungkapkan bahwa tidak ada hubungan yang signifikan antara Citra Tubuh dengan Kecenderungan Bulimia Nervosa pada Model Remaja Putri. Hal ini didukung oleh data statistik yang menjelaskan bahwa nilai $\mathrm{r}$ hitung lebih kecil dari $\mathrm{r}$ tabel yaitu $0.058<0.364$. Maka dapat dikatakan bahwa antara citra tubuh dengan kecenderungan bulimia nervosa tidak memiliki hubungan yang siginifikan antara satu sama lainnya.

\section{Tabel 2}

Persebaran Skor Kecenderungan Bulimia Nervosa

\begin{tabular}{|l|c|c|c|}
\hline \multicolumn{1}{|c|}{ Kategori } & Rentang Skor & Frekuensi & $\%$ \\
\hline Tinggi & $120<x \leq 160$ & 8 & $13 \%$ \\
\hline Sedang & $80<x \leq 120$ & 50 & $81 \%$ \\
\hline Rendah & $40<x \leq 80$ & 4 & $6 \%$ \\
\hline Jumlah & & 62 & $100 \%$ \\
\hline
\end{tabular}

Sumber: Uji Statistik oleh Peneliti

Dari 62 orang responden pada Tabel 2 di atas didapatkan 8 orang diantaranya $(13 \%)$ memiliki skor kecenderungan bulimia nervosa yang masuk dalam kategori tinggi, 50 orang (81\%) masuk dalam kategori sedang, dan 4 orang (6\%) memiliki kategori rendah. Ini menunjukkan bahwa pada subjek model remaja putri, mereka sudah memiliki kecenderungan untuk gangguan bulimia nervosa dalam tingkat kategori sedang. Dengan demikian, tidak menutup kemungkinan jika mereka dewasa akan mengalami gangguan bulimia nervosa. Hal ini dapat terjadi karena tuntutan peran remaja putri sebagai model, yang harus menjaga bentuk tubuh mereka agar tetap langsing dan terlihat indah dimata para designer.

Pada Tabel 3 tentang persebaran skor citra tubuh (lihat halaman berikut), 
dari 62 orang responden, 8 orang (13\%) masuk kategori sangat puas pada citra tubuhnya, 51 orang (82\%) masuk kategori puas pada citra tubuhnya, 3 orang (5\%) masuk kategori netral pada citra tubuhnya, dan tidak ada seorang pun yang masuk kategori tidak puas dan sangat tidak puas pada citra tubuhnya. Hal ini menunjukkan bahwa pada subjek model remaja putri lebih banyak yang masuk kategori puas terhadap citra tubuh. Ini menunjukkan bahwa model remaja putri memiliki penilaian yang cukup positif terhadap citra tubuhnya. Tetapi pada model remaja putri yang masuk kategori netral dapat terjadi karena ada penilaian tersendiri terhadap citra tubuhnya yang kurang memuaskan.

Tabel 3

Persebaran MBSRQ Responden

\begin{tabular}{|l|c|c|c|}
\hline \multicolumn{1}{|c|}{ Kategori } & Rentang Skor & Frekuensi & $\%$ \\
\hline Sangat puas & $289<x \leq 345$ & 8 & $13 \%$ \\
\hline Puas & $234<x \leq 289$ & 51 & $82 \%$ \\
\hline Netral & $179<x \leq 234$ & 3 & $5 \%$ \\
\hline Tidak puas & $124<x \leq 179$ & 0 & 0 \\
\hline Sangat tidak puas & $69<x \leq 124$ & 0 & 0 \\
\hline Jumlah & & 62 & $100 \%$ \\
\hline
\end{tabular}

Sumber: Uji Statistik oleh Peneliti

Bulimia nervosa lebih sering ditemukan pada wanita dibandingkan lakilaki, tetapi lebih sering ditemukan pada remaja atau dewasa awal. Gejala yang sering ditemukan, seperti memuntahkan kembali makanannya, mengkonsumsi obat pencahar, makan yang berlebihan, dan mengalami gangguan pada sistem pencernaan. Walaupun bulimia nervosa lebih sering ditemukan pada remaja putri dengan berat badan normal, mereka kadang-kadang memiliki riwayat kegemukan. Mereka prihatin tentang citra tubuh dan penampilannya, khawatir tentang bagaimana orang lain memandang dirinya, dan prihatin tentang daya tarik seksualnya (Kapplan dan Sadock 1997).

Menurut Wright (Santrock 2003), harapan seseorang terhadap body image yang ideal akan terus menguat sampai remaja. Tobin-Richards, Boxer \& Petersen (Santrock 2003) menambahkan bahwa remaja perempuan memiliki kecenderungan untuk bersikap positif terhadap tubuh mereka ketika sedang merasa mengalami kekurangan berat badan (underweight). Kepuasan remaja akan citra tubuhnya menjadi sangat penting dan dapat menunjukkan peranan yang signifikan dalam memprediksi munculnya depresi, gangguan makan, dan self esteem rendah (Jones, dalam Thompson 1996) .

Dari penjelasan di atas dapat kita lihat bahwa masa remaja ingin menunjukkan citra tubuhnya. Dimana remaja putri ingin menunjukkan citra tubuh dan penampilannya, sehingga dapat menimbulkan kekhawatiran akan bagaimana orang lain memandang dirinya, dan daya tarik terhadap lawan jenis. Sehingga bagi 
remaja putri kepuasan akan citra tubuh sangat penting dan dapat menunjukkan peranannya di masyarakat. Peranan yang penting dapat menimbulkan depresi, gangguan makan dan self esteem yang rendah. Namun, pengertian ini bertolak belakang dengan hasil penelitian ini.

Pada penelitian sebelumnya, dalam karya Helena (2006) yang berjudul Hubungan antara Citra Tubuh dengan Perilaku Makan Pada Penari Tarian Modern Wanita di Jakarta didapatkan hasil bahwa ada hubungan yang signifikan antara citra tubuh dengan perilaku makan pada penari tarian modern wanita di Jakarta. Dengan hasil $r$ hitung 0,381, dibandingkan dengan $r$ tabel (2-tailed) sebesar 0,1967 berdasarkan taraf signifikansi sebesar 0,05 dengan subjek sebesar 100 orang.

Tetapi penelitian Helena tidak sejalan dengan penelitian ini. Hal ini dapat dikarenakan beberapa faktor, yaitu karena berbeda subjek, jumlah subjek yang berbeda, variable yang diukur, dan perbedaan institusi subjek.

Tabel 4

Skor Kecenderungan Bulimia Nervosa Berdasarkan Usia

\begin{tabular}{|l|c|c|c|c|}
\hline \multirow{2}{*}{ Usia } & \multicolumn{2}{|c|}{ Kecenderungan Bulimia Nervosa } & \multirow{2}{*}{ Total } \\
\cline { 2 - 4 } & Tinggi & Sedang & Rendah & \\
\hline \multirow{2}{*}{$13-16$ thn } & 2 & 17 & 3 & 22 \\
\cline { 2 - 4 } & $3.2 \%$ & $27.4 \%$ & $4.8 \%$ & $35.5 \%$ \\
\hline \multirow{2}{*}{$17-20$ thn } & 6 & 33 & 1 & 40 \\
\cline { 2 - 4 } & $9.7 \%$ & $53.2 \%$ & $1.6 \%$ & $64.5 \%$ \\
\hline Total & 8 & 50 & 4 & 62 \\
\cline { 2 - 4 } & $12.9 \%$ & $80.6 \%$ & $6.5 \%$ & $100 \%$ \\
\hline
\end{tabular}

Sumber: Uji Statistik oleh Peneliti

Pada persebaran skor rentang usia di Tabel 4 di atas, didapatkan bahwa skor tertinggi pada kecenderungan bulimia nervosa berada pada kategori sedang dengan rentang usia 17-20 tahun, 33 orang (53.2\%). Ini menunjukkan bahwa pada subjek model remaja putri, mereka rata-rata ada kecenderungan untuk gangguan bulimia nervosa. Walaupun demikian, ada juga model remaja putri yang masuk dalam kategori tinggi untuk kecenderungan gangguan bulimia nervosa, sehingga tidak menutup kemungkinan di usia mereka yang sudah dewasa akan mengalami gangguan bulimia nervosa. Hal ini dapat terjadi karena tuntutan peran remaja putri sebagai model, yang harus menjaga bentuk tubuh mereka agar tetap langsing.

Uji statistik juga menunjukkan bahwa model remaja putri (rentang usia 1720 tahun) memiliki penghayatan yang cukup positif terhadap citra tubuhnya yang sudah menunjang karirnya sebagai model. Kesimpulan ini ditarik dari analisis statistik, sebagaimana hasilnya dapat disimak dalam Tabel 5 di halaman berikut. Tampak di dalam tabel bahwa skor tertinggi pada citra tubuh dimiliki oleh remaja putri rentang usia 17-20 tahun yang menyatakan puas (31 orang, 50\%). Sementara di rentang usia yang sama, terdapat 7 orang yang menyatakan sangat puas $(11.3 \%)$. 
Tabel 5

Skor Citra Tubuh (MBSRQ) Berdasarkan Usia

\begin{tabular}{|c|c|c|c|c|c|c|}
\hline \multirow[b]{2}{*}{ Usia } & \multicolumn{5}{|c|}{ MBSRQ } & \multirow[b]{2}{*}{ Total } \\
\hline & $\begin{array}{c}\text { Sangat } \\
\text { Puas }\end{array}$ & Puas & Netral & $\begin{array}{l}\text { Tidak } \\
\text { Puas }\end{array}$ & $\begin{array}{c}\text { Sangat } \\
\text { Tidak Puas }\end{array}$ & \\
\hline \multirow[t]{2}{*}{$13-16$ thn } & 1 & 20 & 1 & 0 & 0 & 22 \\
\hline & $1.6 \%$ & $32.3 \%$ & $1.6 \%$ & $0 \%$ & $0 \%$ & $35.5 \%$ \\
\hline \multirow[t]{2}{*}{$17-20$ thn } & 7 & 31 & 2 & 0 & 0 & 40 \\
\hline & $11.3 \%$ & $50 \%$ & $3.2 \%$ & $0 \%$ & $0 \%$ & $64.5 \%$ \\
\hline \multirow{2}{*}{ Total } & 8 & 51 & 3 & 0 & 0 & 62 \\
\hline & $19.9 \%$ & $82.3 \%$ & $4.8 \%$ & $0 \%$ & $0 \%$ & $100 \%$ \\
\hline
\end{tabular}

Sumber: Uji Statistik oleh Peneliti

Pada persebaran skor rentang tinggi badan tabel citra tubuh didapatkan skor tertinggi berada pada kategori puas pada rentang tinggi badan 165-170 cm, 21 orang $(33.9 \%)$. Hal ini menunjukkan bahwa mereka menghayati citra tubuhnya cukup positif. Tabel 6 di bawah ini menunjukkan kesimpulan tersebut.

Tabel 6

Skor Citra Tubuh (MBSRQ) Berdasarkan Tinggi Badan

\begin{tabular}{|c|c|c|c|c|c|c|}
\hline \multirow{2}{*}{$\begin{array}{l}\text { Tinggi } \\
\text { Badan }\end{array}$} & \multicolumn{5}{|c|}{ MBSRQ } & \multirow[b]{2}{*}{ Total } \\
\hline & $\begin{array}{c}\text { Sangat } \\
\text { Puas }\end{array}$ & Puas & Netral & $\begin{array}{l}\text { Tidak } \\
\text { Puas }\end{array}$ & $\begin{array}{c}\text { Sangat } \\
\text { Tidak Puas }\end{array}$ & \\
\hline \multirow[t]{2}{*}{$165-170 \mathrm{~cm}$} & 3 & 21 & 0 & 0 & 0 & 24 \\
\hline & $4.8 \%$ & $33.9 \%$ & $0 \%$ & $0 \%$ & $0 \%$ & $38.7 \%$ \\
\hline \multirow[t]{2}{*}{$171-175 \mathrm{~cm}$} & 3 & 18 & 2 & 0 & 0 & 23 \\
\hline & $4.8 \%$ & $29 \%$ & $3.2 \%$ & $0 \%$ & $0 \%$ & $37 \%$ \\
\hline \multirow[t]{2}{*}{$176-180 \mathrm{~cm}$} & 2 & 12 & 1 & 0 & 0 & 15 \\
\hline & $3.2 \%$ & $19.4 \%$ & $1.6 \%$ & $0 \%$ & $0 \%$ & $24.2 \%$ \\
\hline \multirow{2}{*}{ Total } & 8 & 51 & 3 & 0 & 0 & 62 \\
\hline & $12.8 \%$ & $82.3 \%$ & $4.8 \%$ & $0 \%$ & $0 \%$ & $100 \%$ \\
\hline
\end{tabular}

Sumber: Uji Statistik oleh Peneliti

Sedangkan pada skor rentang berat badan tabel citra tubuh didapatkan skor tertinggi berada pada kategori puas pada rentang badan $46-50 \mathrm{~kg}$, yaitu 28 orang (45.2\%). Ini menunjukkan bahwa model remaja putri memiliki penghayatan yang cukup positif pada berat badannya. Tabel 7 di halaman berikut menggambarkan skor citra tubu berdasarkan berat badan. 
Tabel 7

Skor Citra Tubuh (MBSRQ) Berdasarkan Berat Badan

\begin{tabular}{|c|c|c|c|c|c|c|}
\hline \multirow[b]{2}{*}{ Berat Badan } & \multicolumn{5}{|c|}{ MBSRQ } & \multirow{2}{*}{ Total } \\
\hline & $\begin{array}{c}\text { Sangat } \\
\text { Puas }\end{array}$ & Puas & Netral & $\begin{array}{c}\text { Tidak } \\
\text { Puas } \\
\end{array}$ & $\begin{array}{c}\text { Sangat } \\
\text { Tidak Puas } \\
\end{array}$ & \\
\hline \multirow[t]{2}{*}{$41-45 \mathrm{~kg}$} & 1 & 16 & 0 & 0 & 0 & 17 \\
\hline & $1.6 \%$ & $25.8 \%$ & $0 \%$ & $0 \%$ & $0 \%$ & $27.4 \%$ \\
\hline \multirow[t]{2}{*}{$46-50 \mathrm{~kg}$} & 6 & 28 & 3 & 0 & 0 & 23 \\
\hline & $9.7 \%$ & $45.2 \%$ & $4.8 \%$ & $0 \%$ & $0 \%$ & $59.7 \%$ \\
\hline \multirow[t]{2}{*}{$51-55 \mathrm{~kg}$} & 1 & 7 & 0 & 0 & 0 & 8 \\
\hline & $1.6 \%$ & $11.3 \%$ & $0 \%$ & $0 \%$ & $0 \%$ & $12.9 \%$ \\
\hline \multirow{2}{*}{ Total } & 8 & 51 & 3 & 0 & 0 & 62 \\
\hline & $12.8 \%$ & $82.3 \%$ & $4.8 \%$ & $0 \%$ & $0 \%$ & $100 \%$ \\
\hline
\end{tabular}

Sumber: Uji Statistik oleh Peneliti

Tabel 8

Skor Kecenderungan Bulimia Nervosa Berdasarkan Pendidikan

\begin{tabular}{|l|c|c|c|c|}
\hline \multirow{3}{*}{ Pendidikan } & \multicolumn{2}{|c|}{ Kecenderungan Bulimia Nervosa } & \multirow{2}{*}{ Total } \\
\cline { 2 - 4 } & Tinggi & Sedang & Rendah & \\
\hline \multirow{3}{*}{ SMP } & 0 & 6 & 2 & 8 \\
\cline { 2 - 5 } & $0 \%$ & $9.7 \%$ & $3.2 \%$ & $12.9 \%$ \\
\hline \multirow{3}{*}{ SMA } & 6 & 30 & 2 & 38 \\
\hline \multirow{3}{*}{ Diploma } & $9.7 \%$ & $48.8 \%$ & $3.2 \%$ & $61.3 \%$ \\
\cline { 2 - 5 } & 1 & 3 & 0 & 4 \\
\hline S1 & 1 & $4.8 \%$ & $0 \%$ & $6.5 \%$ \\
\cline { 2 - 5 } & $1.6 \%$ & 11 & 0 & 12 \\
\hline Total & 8 & 50 & $0 \%$ & $19.4 \%$ \\
\cline { 2 - 5 } & $12.9 \%$ & $80.6 \%$ & $6.5 \%$ & 62 \\
\hline
\end{tabular}

Sumber: Uji Statistik oleh Peneliti

Berdasarkan persebaran skor tingkat pendidikan seperti tergambar dalam Tabel 8, sebagian model berpendidikan SMA 30 orang $(48,4 \%)$ memiliki kecenderungan bulimia nervosa pada kategori sedang, berikutnya sejumlah 11 orang $(17.7 \%)$ berpendidikan S1 juga memiliki kecenderungan bulimia nervosa 
pada kategori sedang. Yang memiliki kecenderungan bulimia nervosa pada kategori tinggi juga terbanyak pada pendidikan SMA sebanyak 6 orang (9.7\%). Hal ini menunjukkan bahwa pada subjek model remaja putri ada kecenderungan untuk bulimia nervosa. Walaupun demikian, terlihat ada model remaja yang masuk kategori tinggi. Dalam hal ini mereka sudah memikirkan untuk tuntutan profesinya. Sedangkan masa remaja mereka masih memerlukan pendidikan dan menyelesaikan tingkat pendidikannya.

Sementara citra tubuh responden berdasarkan tingkat pendidikan menunjukkan bahwa, skor tertinggi berada pada kategori puas pada tingkat pendidikan SMA sebanyak 32 orang (51.7\%). Hal ini menunjukkan bahwa pada subjek remaja putri, mereka cukup memiliki penghayatan positif pada keadaan fisik saat ini yang menunjang karirnya sebagai model. Tetapi masih terlihat ada 3 (tiga) orang (4.8\%) yang masuk kategori netral pada tingkat pendidikan S1 dan SMA, ini menunjukkan mereka masih memiliki penilaian yang kurang puas pada fisiknya dan memikirkan bentuk fisik yang sesuai untuk menunjang karirnya. Lebih detail periksa Tabel 9 di bawah ini.

Tabel 9

Skor Citra Tubuh (MBSRQ) Berdasarkan Pendidikan

\begin{tabular}{|c|c|c|c|c|c|c|}
\hline \multirow{2}{*}{$\begin{array}{l}\text { Tinggi } \\
\text { Badan }\end{array}$} & \multicolumn{5}{|c|}{ MBSRQ } & \multirow[b]{2}{*}{ Total } \\
\hline & $\begin{array}{c}\text { Sangat } \\
\text { Puas }\end{array}$ & Puas & Netral & $\begin{array}{c}\text { Tidak } \\
\text { Puas }\end{array}$ & $\begin{array}{c}\text { Sangat } \\
\text { Tidak Puas }\end{array}$ & \\
\hline \multirow[t]{2}{*}{ SMP } & 0 & 8 & 0 & 0 & 0 & 8 \\
\hline & $0 \%$ & $12.9 \%$ & $0 \%$ & $0 \%$ & $0 \%$ & $12.9 \%$ \\
\hline \multirow[t]{2}{*}{ SMA } & 5 & 32 & 1 & 0 & 0 & 38 \\
\hline & $8.1 \%$ & $51.7 \%$ & $1.6 \%$ & $0 \%$ & $0 \%$ & $61.4 \%$ \\
\hline \multirow[t]{2}{*}{ Diploma } & 2 & 2 & 0 & 0 & 0 & 4 \\
\hline & $3.2 \%$ & $3.2 \%$ & $0 \%$ & $0 \%$ & $0 \%$ & $6.4 \%$ \\
\hline \multirow{2}{*}{ S1 } & 1 & 9 & 2 & 0 & 0 & 12 \\
\hline & $1.6 \%$ & $14.5 \%$ & $3.2 \%$ & $0 \%$ & $0 \%$ & $19.3 \%$ \\
\hline \multirow{2}{*}{ Total } & 8 & 51 & 3 & 0 & 0 & 62 \\
\hline & $12.8 \%$ & $82.3 \%$ & $4.8 \%$ & $0 \%$ & $0 \%$ & $100 \%$ \\
\hline
\end{tabular}

Sumber: Uji Statistik oleh Peneliti

Hasil yang didapatkan setelah melakukan penelitian terhadap 62 orang remaja putri yang berprofesi sebagai model adalah tidak ada hubungan antara citra tubuh dengan kecenderungan bulimia nervosa pada model remaja putri. Hal ini berarti, teori ini tidak dapat digeneralisasikan terhadap seluruh keriteria responden.

Beberapa model remaja putri di Jakarta mengakui mengalami gangguan makan tetapi bagi mereka tidak mengganggu aktivitas sehari-harinya yang juga 
sebagai pelajar. Hal ini dikarenakan bahwa menurut mereka sebagai seorang model harus memiliki tubuh yang langsing dan indah, agar enak dilihat oleh para designer dan penonton.

Keterbatasan dalam penelitian ini diantaranya adalah kecilnya lingkup penelitian, yaitu hanya di empat agency modelling di Jakarta. Sehingga kurang diperoleh gambaran bagaimana hubungan antara citra tubuh dengan kecenderungan bulimia nervosa pada model remaja putri. Karena kemungkinan adanya perbedaan pada masing-masing institusi bisa saja terjadi. Oleh karena itu, hasil penelitian ini belum bisa digeneralisasikan pada seluruh model remaja putri, namun hanya terbatas pada responden penelitian saja. Kurangnya kondusif situasi tes, karena perbedaan tempat dalam pengisian kuesioner. Dalam instrumen kecenderungan gangguan bulimia nervosa ada beberapa item yang berkaitan dengan citra tubuh, oleh karena itu penelitian selanjutnya yang akan mengukur dapat mempertimbangkan, membuang atau memperbaiki item.

\section{Kesimpulan}

Berdasarkan analisis data, maka diperoleh kesimpulan dari penelitian ini bahwa tidak ada hubungan negatif yang signifikan antara citra tubuh dengan kecenderungan bulimia nervosa pada model remaja putri. Artinya citra tubuh yang positif para model tidak diikuti dengan menurunnya kecenderungan gangguan bulimia nervosa secara signifikan. 


\section{Daftar Pustaka}

Arikunto, S. 2002. Metodologi Penelitian Suatu Pendekatan Proposal. Jakarta: Rineka Cipta.

Atwater, E \& Duffy, K. G. 1999. Psychology For Living Adjustment, Growth, and Behavior Today (6th ed). New Jersey: Prentice Hall, Inc.

Davison, G. C, J. M. Neale, A. M. Kring. 2006. Psikologi Abnormal. Jakarta: RajaGrafindo Persada.

Diagnostic and Statistical Manual of Mental Disorders 4th Edition. 2000. Washington: American Psychiatric Association.

Fasli, F. I. 2005. Kepuasan Citra Tubuh pada Remaja Putri. Skripsi Sarjana. Depok: Fakultas Psikologi Universitas Indonesia.

Helena, A. 2006. Hubungan antara Citra Tubuh dengan Perilaku Makan Pada Penari Tarian Modern Wanita di Jakarta. Skripsi Sarjana. Jakarta: Fakultas Psikologi Universitas Atma Jaya.

Herron, R \& V.J. Peter. 2003. I Love Me: Gimana Jadi Remaja Pede and Smart. Bandung: Kaifa.

Kaplan, H. I., B. J. Sadock, J. A. Grebb. 1997. Sinopsis Psikiatri. Jakarta: Binarupa Aksara

Kemala, Jihan. 2002. Kepuasan Citra Tubuh pada Remaja Wanita Peserta Senam Body Language. Skripsi Sarjana. Depok: Fakultas Psikologi Universitas Indonesia.

Papalia, D. E., Old, S. W., dan Feldman, R. D. 2008. Human Development: Psikologi Perkembangan. Jakarta: Kencana.

Rice, P. F. 1990. The Adolescent: Development, Relationship and Culture. Boston: Allyn \& Bacon.

Santrock, J. W. 2003. Adolescense: Perkembangan Remaja. Jakarta: Erlangga.

Sari, Muna Eka. 2006. Hubungan antara Kepuasan Citra Tubuh dengan Kepercayaan Diri pada Remaja. Skripsi Sarjana. Ciputat: Fakultas Psikologi Universitas Islam Negeri Syarif Hidayatullah Jakarta.

Sugiyono. 2002. Metode Penelitian Bisnis. Bandung: Alfabeta.

Thompson, K. J. 1996. Eating Disorders, Body Image E Obesity: an Integrative Guide for Assessment and Treatment. USA: American Psychology Association.

Thompson, J. Kevin, Heinberg. J. Leslie, Altabe, Medeline \& Tantlef -Dunn, Stacey. 1999. Exacting Beauty: Theory, Assessment, and Treatment of Body Image Disturbance. American Psychological Association, Washington DC. 


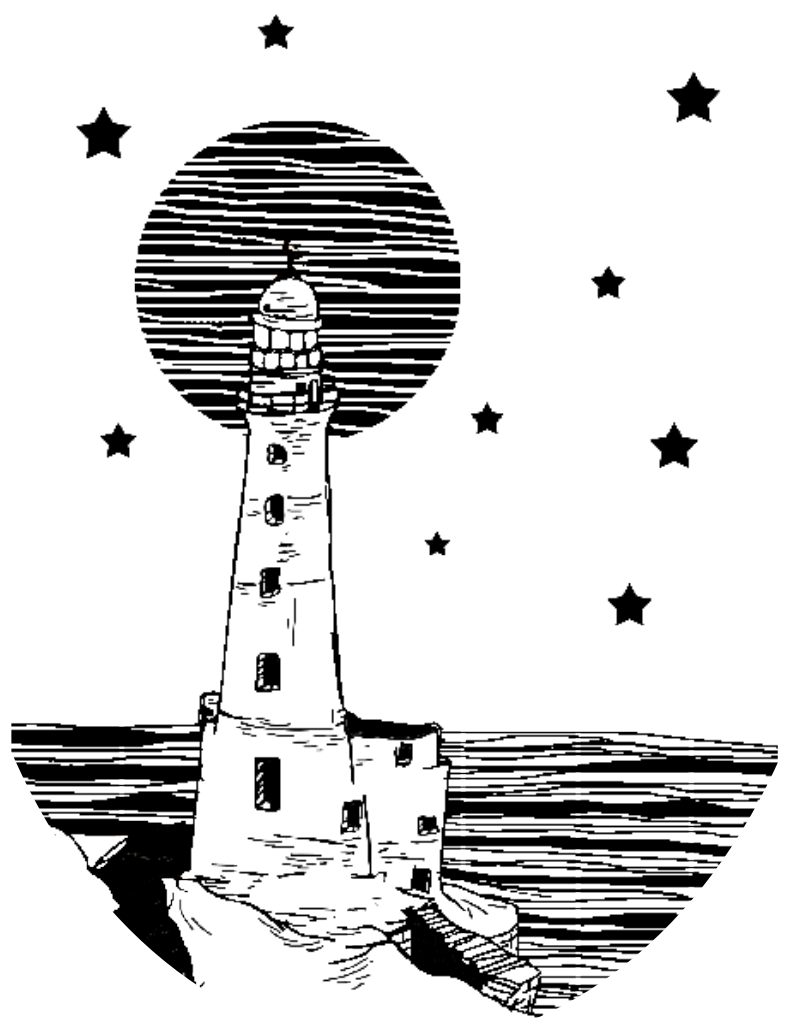

